\title{
Blaming threatened species: media portrayal of human-wildlife conflict
}

\author{
Ashley A. Dayer, Alicia Williams, Emily Cosbar and Meagan Racey
}

\begin{abstract}
Recent literature has urged the conservation science community to distinguish between human-wildlife and human-human conflict. Mislabelling conflicts is thought to constrain problem definition and hinder appropriate solutions. New to this discussion, we studied how the media is framing conflict. The focus of our research was conflict surrounding conservation of a protected species. The piping plover Charadrius melodus is federally listed as threatened on the Atlantic coast of the USA. Our research focused on characterizing the tone and framing in media coverage of the plover and its conservation. We were interested in how the source of the conflict was framed: are the species itself, policies, or the government agencies administering legal restrictions blamed for the conflict? We analysed 725 articles (199 unique articles, not including those run by multiple media sources) written about the plover in the region during January 2014-September 2015. Articles were analysed qualitatively by two coders. We found the overall tone of the unique articles was most frequently positive towards the bird and/or its conservation (48\%), followed closely by neutral (or balanced) articles (46\%). Few articles were negative $(6 \%)$. Nonetheless, framing that blamed a source for the conflict was present in $34 \%$ of the unique articles. The plover itself was blamed in twice as many articles as the policies or government agencies enacting the regulations. This framing was also the strongest predictor of article tone. Understanding how the media portrays piping plovers can help guide organizations interested in proactive media relations and other solutions to de-escalate this conflict.
\end{abstract}

Keywords Charadrius melodus, framing, human-wildlife conflict, media analysis, piping plover, shorebird, social conflict, threatened species

\section{Introduction}

$\mathrm{A}_{\mathrm{t}}^{\mathrm{l}}$ lthough human-wildlife conflict often involves predators or pests, conflict over how to conserve federally

Ashley A. DAyer (Corresponding author) Virginia Tech, Department of Fish and Wildlife Conservation, 310 West Campus Drive, 108 Cheatham Hall, Blacksburg, VA 24061, USA. E-mail dayer@vt.edu

Alicia Williams and Emily Cosbar Cornell Lab of Ornithology, Ithaca, New York, USA

Meagan Racey U.S. Fish and Wildlife Service, Hadley, Massachusetts, USA

Received 20 December 2016. Revision requested 9 March 2017.

Accepted 2 May 2017. First published online 18 July 2017. protected species can be just as heated, pitting groups of people against one another and implicating wildlife. Conflict occurs 'when the needs and behaviour of wildlife impact negatively the goals of humans or when the goals of humans negatively impact the needs of wildlife' (Madden, 2004). Most commonly, these conflicts occur when people and wildlife compete for the same resource, such as habitat or recreational space (Jorgensen \& Bomberger Brown, 2015). Moreover, if people perceive that the needs or values of wildlife are given priority over their own needs, conflict escalates (Madden, 2004). Legislation, regulations and policies implemented to protect or conserve specific wildlife species and their habitats, such as the federal Endangered Species Act in the USA, can result in social and economic costs that lead to a perception of conflict between people and wildlife (Messmer, 2000), when in fact it is often social conflict over conservation activities.

Although human-wildlife conflict is defined as humans in conflict with wildlife, it often has an underlying dimension of human-human conflict (Manfredo \& Dayer, 2004; Dickman, 2010). These conflicts are sometimes manifestations of underlying conflicts between authorities and local people (Dickman, 2010), as in the case of the Endangered Species Act, which creates restrictions at the local level. Recent publications have urged the conservation and management community to distinguish between human-wildlife and human-human conflicts (Peterson et al., 2010; Young et al., 2010; Redpath et al., 2015). Redpath et al. (2015) found that the majority of the peer-reviewed science literature labelled as human-wildlife conflict is actually focused on conflict between people supporting measures to conserve wildlife and people advocating prioritization of human activities and livelihoods. Similarly, Peterson et al. (2010) showed that literature on wildlife conflict is typically about damage to property or conflict over how to conserve or manage a species (e.g. threatened species), and rarely about true human-wildlife conflict. Mislabelling conflicts is thought to constrain problem definition and hinder appropriate solutions (Peterson et al., 2010). Whereas effective solutions to human-human conflict would probably involve building trust and fostering dialogue, solutions proposed to address human-wildlife conflict are typically technical (Young et al., 2010). Recent attention to the framing of conflicts is leading to new techniques targeting coexistence (Fisher, 2016).

In addition to how scientists frame conflict, it is also important to consider how the media is framing the conflict. The argument of Redpath et al. (2015) for appropriate 
labelling of conflict hinges on the role of the media, even though the authors studied only scientific publications. They explain that the way conflict is framed by the media has repercussions, such as the media's effects on the political agenda or priming readers. Yet there has been no analysis of the media's framing of conflict over wildlife conservation and management as human-wildlife or human-human conflict. We present the first such study, focusing on a specific case of conflict over a threatened species, the piping plover Charadrius melodus on the Atlantic coast of the USA, which is at the centre of conflict because of its federally protected status. Based on definitions by Peterson et al. (2010) and Redpath et al. (2015) this is a case of humanhuman conflict, but we are interested in how the media framed this issue.

\section{Literature review}

The Endangered Species Act conserves endangered and threatened species in the USA, with conservation defined as the use of all methods and procedures necessary to bring the species to the point where these measures are no longer needed. The U.S. Fish and Wildlife Service and the National Marine Fisheries Service designate which species are endangered or threatened. To some, the Act is not aggressive enough in its protection of species (Scott et al., 1987). However, others think it overprotects species (Bornemeier, 1995). One criticism at the root of the conflict over the Endangered Species Act is the perception that it gives the federal government too much authority over private lands where endangered and threatened species occur (Kishida, 2001). Furthermore, people become frustrated by the Act's influence over federal projects (Thompson, 1997). Restrictions made to protect listed species can result in unintended harm to the livelihoods of communities (Benson, 2002). Conflict also arises over listed species as a result of direct negative interactions with people, such as predation on livestock or game, crop-raiding or destruction of stored food, attacks on people, or disease transmission to livestock or people (Dickman, 2010). One of the best known conflicts over a listed species in the USA involved the grey wolf Canis lupus, which came into conflict with people because of predation of livestock and other perceived potential threats to people (Treves et al., 2002). This conflict became even more complicated when the species was reintroduced as a federally protected species and limitations were made on how people could respond to wolf predation.

Conflict is becoming of increasing concern to conservationists because it is one of the most critical threats to wildlife (Dickman, 2010). For almost all species under threat, conflicts with people are believed to be the most serious threat (Woodroffe et al., 2005). Anthropogenic impacts on wildlife may be equally, if not more, severe for federally listed species in the USA regardless of whether they are predators, pests, disease vectors, or rarely interact with people. This notion is evidenced by reports of habitat destruction in anticipation of a new listing (Brown \& Shogren, 1998). Landowners have declined to participate in biological surveys of their land, or specifically altered land management practices to avoid potential land-use constraints associated with a listed species (Brook et al., 2003). Individual landowners and private firms sometimes choose to destroy habitat rather than face potential restrictions associated with the listing of an endangered species, countering the intended goals of the policy (Lueck \& Michael, 2003). This conflict suggests a challenge to the effectiveness of the Endangered Species Act. From the perspective of conservation effectiveness, the phenomenon where the listing of the species creates conflict, resulting in less compliance and activities that run counter to conservation efforts, needs to be better understood so it can be prevented or mitigated. Consideration of human dimensions through social science research is essential, as in other more traditional wildlife conflict scenarios, because 'the thoughts and actions of humans ultimately determine the course and resolution of the conflict' (Manfredo \& Dayer, 2004, p. 317).

In the case of the piping plover, this species does not negatively affect people by destroying crops or attacking people or livestock in the way carnivores or pests would. Rather, efforts to conserve the plover, which has been protected under the Endangered Species Act since 1986, have resulted in conflict over this small shorebird species that nests on popular beaches along the Atlantic Coast of the USA. Current species recovery plans suggest reducing the disturbance of plovers by people by means of a variety of techniques, such as posting, staking and twining nesting areas, limiting driving on beaches, and leashing pets (USFWS, 1996). These techniques are considered by some to be restrictive of the activities of people on beaches. As the bird's breeding season coincides with the season when people prefer to use beaches, individuals may feel their recreational activities are restricted. An additional source of conflict has resulted from the widespread desire to stabilize shorelines to protect infrastructure and prevent beaches from shifting in response to storms, sea-level rise and other natural processes. When beaches respond naturally to these events and processes they return to open, low-lying sandy beaches with moist areas for birds to forage. Plovers are well adapted to the shifting sands of the beach and, along with other beach-reliant wildlife, rely on these areas (USFWS, 1996).

To explore this conflict we conducted a media analysis. Media analysis is defined as a 'systematic method to study mass media' (Macnamara, 2005). It is 'the analysis of what is contained in a message' (Prasad, 2008). Media analysis is useful for understanding the human dimensions of a conflict issue because the media has a great influence on perceptions and affective responses of audiences (Gore et al., 2005; Gore \& 
Knuth, 2009). Furthermore, media analysis has been shown to provide a cost-effective approach for understanding the social aspects of conflict about wildlife (Houston et al., 2010). This approach has been applied in natural resource settings, including flood resilience (Bohensky \& Leitch, 2014), wolves (Houston et al., 2010), and carbon capture and storage (Feldpausch-Parker et al., 2015). Media analysis often focuses on understanding the tone of an article as an indication of public attitudes towards an issue or topic, such as a wildlife species (e.g. Houston et al., 2010) or a new/experimental technology (e.g. Feldpausch-Parker et al., 2015).

The framing of an issue can also be explored through media analysis (e.g. by deconstructing media along the lines of a narrative; Bohensky \& Leitch, 2014). Tankard (2001, p. 100) defined framing as 'a central organizing idea for news content that supplies a news context and suggests what the issue is through the use of selection, emphasis, exclusion, and elaboration'. Framing can also have effects on how the readers of a story understand an issue, depending on the characteristics of the audience and how they process mass media messages (Scheufele \& Tewksbury, 2007).

We were interested in using media analysis to answer the following specific questions: (1) What is the prevalent tone of news media coverage of piping plovers towards plovers and their conservation (i.e. positive/neutral/negative)? (2) How do media articles frame the conflict over activities associated with plover conservation: plovers to blame, government agencies to blame, or policies to blame? (3) What are the predictors of the tone of an article (e.g. affiliation of spokesperson, season, frame)?

\section{Methods}

Articles for this media analysis were collected by Meltwater Group, an international media intelligence firm. Their system collected 3,187 articles that mentioned piping plovers, published during January 2014-September 2015. Of these, we selected the articles that focused primarily on piping plovers in the Atlantic Flyway (i.e. the north-east and south-east USA) and were published by news media sources (e.g. excluding informal blogs and NGO websites). Articles that could not be accessed online were excluded because they could not be analysed qualitatively. After these exclusions, a total of 725 articles remained for analysis. If the same article was run by a number of media sources, we selected one source at random for inclusion in the analysis to ensure that a single article and its characteristics were not disproportionately represented in our analysis. The resulting sample was 199 articles.

\section{Coding and variables}

The database provided by Meltwater Group included the outlet/publication, country, date, headline, and URL.
A coding scheme (see below) was developed to analyse the tone of the article as well as the hypothesized predictors of the tone. Two coders read and coded an initial set of 10 articles independently. They met after coding these articles to discuss any discrepancies in their codes and to further revise the coding scheme. They continued to meet throughout the process to discuss discrepancies. We conducted an intercoder reliability analysis with a subset of the articles $(n=50)$ for all of the tone and source-of-blame variables. We found that the coders reported different codes for no more than four articles for any of the tone variables ( $92 \%$ agreement or higher) and there were no discrepancies for any of the source-of-blame variables (100\% agreement). The final codes used for analysis reflected the consensus interpretations of both coders after discussion.

The tone of the headline was coded as positive $(+1)$, negative $(-1)$, or neutral (o) towards plovers and their conservation. Positive statements emphasized that plovers and/or plover conservation were important; neutral statements did not indicate an evaluation of whether plovers or related activities were good or bad, or presented good and bad evaluations in equal proportions; and negative statements described problems with piping plovers and associated conservation activities. We acknowledge that positive and negative tones can have different meanings based on an individual's beliefs about wildlife (Manfredo \& Dayer, 2004), but we followed the approach of other conflict studies in the literature that define positive tones as having a pro-wildlife sentiment and negative tones as having anti-wildlife or pro-human sentiments (Houston et al., 2010; Bhatia et al., 2013).

Using the same definitions as above, we also coded the tone of the body of the article as positive $(+1)$, negative $(-1)$ or neutral (o). The body of the article was considered to be everything in the text of the article except quotes or implied quotes. We also coded for the tone of the quotes in the article. Using the above criteria we evaluated each quote and indicated which types of quotes were present. Finally, for overall tone, we took into consideration the tone of the headline, body and quotes, and determined whether the article was positive, negative or neutral. If an article comprised a majority of negative or positive elements, we coded it accordingly. We coded for neutral if an article had either equal parts negative and positive elements, or consisted of mostly neutral elements.

We also analysed the articles for framing the source of blame for the conflict over the piping plover as the piping plover itself, policies (e.g. Endangered Species Act or local policies), or the government (e.g. U.S. Fish and Wildlife Service or local government) implementing protection. For the category of piping plovers to blame, we examined whether or not the quotes or body of the article framed plovers as problematic, as opposed to other outside factors. An example of this framing would be the suggestion that plovers were responsible for stalling a construction project. 
Alternatively, we coded framing of policies to blame in cases in which articles suggested that laws, legislation or policies were causing the problem (e.g. blaming leash laws for hindering rights to recreational dog-walking on beaches). Framing of government to blame referred attributions of responsibility to a specific government agency or the government generally in the quotes or body of the article (e.g. 'the government cares more about protecting the plovers than the people').

We also coded articles for the presence of categories of spokespeople (those quoted in the article): unidentified, local resident, tourist, U.S. Fish and Wildlife Service, local government, state government, non-U.S. Fish and Wildlife Service government, NGO, and industry. We indicated whether the article was published in the plover wintering season (September-February) or the breeding/nesting season (March-August). We also recorded if the U.S. Fish and Wildlife Service Northeast Regional Office External Affairs staff frequently worked with the source of the article (based on a list they provided, including The Portland Press Herald, Associated Press, Bangor Daily News, Boston Globe, Cape Cod Times, KeepMECurrent, Press of Atlantic City, News Day, Mainely Media/Scarborough Leader, and Wicked Local/Cape Codder/Orleans).

\section{Statistical analysis}

All statistical analysis was conducted using SPSS v. 23 (IBM, Armonk, USA). We calculated descriptive statistics of variables, including frequency counts and percentages. To ascertain which variables predicted overall tone, we conducted Spearman's rank order correlations between overall tone and the tone in particular parts of the article, presence of quotes from various types of spokespeople, characteristics of the news (i.e. season published, target news source), and whether each type of source-of-blame framing was present (i.e. whether the whole or part of the article framed plovers, policies or government agencies as being to blame for the conflict). We also conducted a logistic regression for predicting overall tone (collapsed to positive vs neutral or negative, given the small number of negative cases) with all variables except those related to tone elsewhere in the article.

\section{Results}

\section{Tone and other characteristics of articles}

The overall tone of the articles was positive (48\%) or neutral (46\%); very few articles conveyed an overall negative tone (6\%). Headlines were most frequently neutral (61\%). Positive headlines were found in $25 \%$ of articles, and negative headlines in only $14 \%$. The tone of the body of $49 \%$ of the articles was neutral, and a positive tone (43\%) was found to be only slightly less frequent. Only $8 \%$ of the articles had a negative tone in the body. In terms of quotes, nearly two-thirds of the articles included at least one neutral quote (69\%). Approximately half of the articles included at least one positive quote ( $44 \%)$, and only $9 \%$ had any negative quotes.

Some of the 199 articles we selected were run by multiple outlets. Considering all of the re-runs of articles $(n=725$ for all articles vs $n=199$ for unique articles), the overall tone was still neutral $(65 \%)$ or positive $(31 \%)$. Only $4 \%$ of the full set of 725 articles were negative.

The most frequently quoted spokespeople (Fig. 1) were those from the state government, followed by local residents and local government, NGOs, U.S. Fish and Wildlife Service, non-U.S. Fish and Wildlife Service, federal government, and other. Unidentified, tourist, and industry spokespeople were rarely quoted in the articles. The other category included such groups as professors or educators.

In the negative articles, the human activities interrupted by conservation restrictions for plovers included the use of vehicles and boats on beaches, access to the beach (e.g. walking a dog, walking with children), rebuilding and replenishing sand on the beach, sand pumping operations, and dune construction. The conservation activities cited in the negative articles were town-implemented habitat conservation plans to protect plovers while allowing access to trails, field technicians working on the beach to protect piping plovers, and a federal complaint filed by The Audubon Society to halt placement of sand in plover habitat. The groups mentioned in the negative articles that were intervening for the benefit of plovers were Mass Audubon, The Audubon Society, the state Department of Environmental Conservation, and federal officials generally. The conservation activities themselves were mentioned in a factual context and were generally not portrayed in the media as positive or negative.

\section{Source-of-blame framing}

Of the 199 articles analysed, 67 contained one or more types of source-of-blame framing ( $34 \%)$, most frequently blaming piping plovers $(28 \%)$. The next most frequent framing was focused on policies $(10 \%)$, with few articles $(3 \%)$ framing the government (local, state or federal) as being to blame. The specific policies we found mentioned in the articles were local animal control ordinances (e.g. requiring dogs to be leashed), local seasonal bans on recreation activities (e.g. kiteboarding), temporary restraining orders on construction, and references to federal and state regulations/restrictions/ policies to protect plovers. No articles framed the Endangered Species Act as being specifically responsible for negative events, although the Act was referenced in 


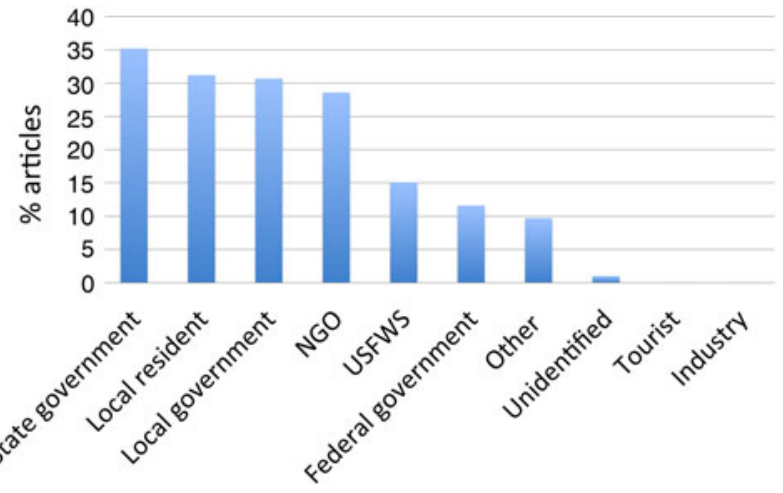

FIG. 1 In descending order, the percentage of a sample of 199 articles on piping plovers Charadrius melodus in the Atlantic Flyway that included a quote from each spokesperson category.

some of the articles in a non-judgmental manner. The government entities framed as being at fault in the articles were the U.S. Fish and Wildlife Service, state Department of Environmental Conservation (New York), town councils, and the federal government generally.

\section{Predictors of tone}

We explored correlations between hypothesized predictor variables and overall tone (Table 1). High correlations were found between overall tone and tone of body (0.90), tone of headline (0.55), and positive quotes (0.46). A medium strength, negative correlation for overall tone was found between overall tone and with both negative quotes $(-0.28)$, and neutral quotes $(-0.20)$. Of the other variables (spokespeople, characteristics of news source, and source-of-blame framing), the plover to blame was the strongest correlate (-0.45). Framing of policies and government to blame were not significantly correlated with the overall tone. The only types of spokespeople that correlated significantly with overall tone were state government (0.22) and non-U.S. Fish and Wildlife Service federal government (-0.18). Season and target news source were not correlated with the overall tone.

In a logistic regression analysis predicting positive tone (as opposed to negative or neutral tone) with all variables except those related to tone elsewhere in the article, the model was statistically significant, $\chi^{2}(11)=44.73, \mathrm{P}<0.001$. The model explained $27.1 \%$ (Nagelkerke $R^{2}$ ) of the variance in overall tone and correctly classified $69.5 \%$ of cases. Articles with source-of-blame framing for plovers were 8.19 times more likely to exhibit a negative or neutral tone than articles without this framing. This variable was the only significant predictor of the tone (Table 2).

\section{Discussion}

Despite increased human-shorebird interaction and conflict with increasing recreation and coastal development,
TABLE 1 Spearman's rank order correlation between hypothesized predictor variables and overall tone of a sample of 199 articles on piping plovers Charadrius melodus in the Atlantic Flyway.

\begin{tabular}{lcc}
\hline Variable & Correlation & $\mathrm{P}$ \\
\hline Tone in various parts of article & & \\
Headline & 0.55 & $<0.001$ \\
Body & 0.90 & $<0.001$ \\
Positive quotes & 0.46 & $<0.001$ \\
Neutral quotes & -0.20 & 0.005 \\
Negative quotes & -0.28 & $<0.001$ \\
Spokespeople & & \\
Local resident & -0.10 & 0.16 \\
Local government & -0.13 & 0.06 \\
State government & 0.22 & 0.002 \\
Non-U.S. Fish \& Wildlife Service & -0.18 & 0.013 \\
federal government & & \\
U.S. Fish \& Wildlife Service & 0.12 & 0.10 \\
Non-governmental organization & -0.06 & 0.44 \\
Characteristics of news source & & \\
Season & 0.12 & 0.10 \\
Target & 0.13 & 0.08 \\
Source of blame framing & & \\
Plovers & -0.45 & $<0.001$ \\
Policies & -0.09 & 0.20 \\
Government agencies & -0.04 & 0.63 \\
\hline
\end{tabular}

and in contrast to expectations of the plover conservation community (Anne Hecht, pers. comm., 1 July 2016), most media coverage of the piping plover during January 2014September 2015 was positive or neutral (including articles with equal parts negative and positive) towards the bird and/or conservation. More negativity was expected given that in other locations, from the Midwest USA to Australia, the sentiments of beach users towards plovers have been reported as negative (Maguire et al., 2013; Jorgenson \& Bomberger Brown, 2015). Possibly, our finding reflects the journalistic best practice of taking a balanced approach to covering topics (Priest, 2015), but this does not explain the preponderance of positive articles as opposed to simply a high frequency of neutral articles.

Having social support for a threatened species and for the programmes implemented to manage its safety is important to the success of species recovery efforts (Maguire et al., 2013). From a conservation perspective, it is therefore troubling that we found over one-third of the articles included source-of-blame framing, and specifically that one-quarter of the articles framed the piping plover as to blame. This suggests that through the implementation of one of the most important wildlife conservation policies in the USA we are seeing human-wildlife rather than human-human conflict reflected in the media. This framing of the plover itself as to blame (i.e. a human-wildlife conflict frame) was also the strongest predictor of a more negative overall tone in articles, which is important as the framing of an 
TABLE 2 Logistic regression results for predictors of overall tone (negative/neutral vs positive) of a sample of 199 articles on piping plovers Charadrius melodus in the Atlantic Flyway.

\begin{tabular}{llc}
\hline Variable & $\operatorname{Exp}(\mathrm{B})$ & $\mathrm{P}$ \\
\hline Spokespeople & & \\
Local resident & 1.40 & 0.53 \\
Local government & 0.74 & 0.61 \\
State government & 0.70 & 0.31 \\
Non-U.S. Fish \& Wildlife Service federal & 2.64 & 0.10 \\
$\quad$ government & & \\
U.S. Fish \& Wildlife Service & 0.54 & 0.22 \\
Non-governmental organization & 1.11 & 0.78 \\
Characteristics of news source & & \\
Season & 1.04 & 0.93 \\
Target & 0.49 & 0.08 \\
Source of blame framing & & \\
Plovers & 8.19 & $<0.001$ \\
Policies & 0.96 & 0.95 \\
Government agencies & 0.82 & 0.84 \\
\hline
\end{tabular}

Model summary statistics: $\chi^{2}(11)=44.73, \mathrm{P}<0.001$

issue can shape and influence public opinion and perceptions (Scheufele \& Tewksbury, 2007; Houston et al., 2010). It is unclear how pervasive blaming of wildlife for conflict is in media coverage of the conservation of other threatened and endangered species, but this warrants investigation. Unlike other protected species for which human-wildlife conflict has been heavily documented when the species had special status and when it did not (e.g. wolves, Treves et al., 2002), without this protection, and subsequent restriction on human behaviour, it is unlikely that piping plovers would be portrayed negatively in the media. Plovers do not predate on human property, nor are they pests. Typically, birds are one of the most loved types of wildlife (Gray, 1993). Yet, our finding of anti-plover sentiment aligns with reports of negative outcomes for other federally protected wildlife species, including unwillingness to cooperate, or even attempts to try to remove endangered species from private lands (Kishida, 2001; Brook et al., 2003).

No articles blamed the Endangered Species Act itself as being directly responsible for negative events. People sometimes become frustrated by its influence over federal projects that benefit private property holders (Thompson, 1997), but although this frustration was acknowledged in negative articles, they did not blame the Act. Policies that were framed negatively in the articles included local animal control ordinances (e.g. requiring dogs to be leashed), local seasonal bans (e.g. banning kiteboarding), and temporary restraining orders on construction, and there were general references to federal and state regulations to protect plovers. This is consistent with the finding of an Australian study that regular beach-goers and dog walkers found it challenging to adapt their behaviour in line with management and policy changes (Maguire et al., 2013).
The U.S. Fish and Wildlife Service, the agency that administers the Endangered Species Act, was framed negatively, in the context of delaying projects, such as coastal river dredging, to protect the piping plover. They were also blamed for fining towns for not protecting plovers. Other authorities were also framed negatively; for example, the Department of Environmental Conservation in New York was blamed for trying to designate land as protected habitat, and at the local level, town councils were portrayed negatively. The framing of government agencies in this way is indicative of conflict between authorities and local people (Dickman, 2010). Yet, this human-human conflict frame was much less common in the media than human-plover conflict framing.

We found the presence of a quote from a state government spokesperson to be positively correlated with tone of articles. However, this does not necessarily mean they contributed positive quotes, only that they were quoted in more positive articles. Yet, given this relationship, it could be helpful for those involved in communication of plover conservation efforts to work more closely with state agencies to share messaging about plovers and maximize positive press opportunities. In contrast, the presence of non-U.S. Fish and Wildlife Service federal government spokespeople was negatively correlated with tone of articles. Many of the negativetone articles with non-U.S. Fish and Wildlife Service federal government spokespeople related to storm recovery efforts, often referring to plovers stalling or causing delays in the projects. We recommend two possible solutions: (1) encouraging project proponents to explain, if appropriate, the other factors that are affecting their timelines, and (2) increased transparency regarding delays caused by plover protection. However, these solutions may not be sufficient to change media coverage, which is likely to reflect public sentiment and frustration when the public is affected by a process in which it is not directly involved. Furthermore, the media may not be influenced by such information, as it is driven most directly by an array of factors such as newsworthiness, deadlines, economic goals, audience interests, and belief systems (Priest, 2015).

This case of conflict over conservation activities for a threatened species is not unique. Anecdotally, similar species are the focus of the same negative attention from the media and public because of their status (e.g. the red knot Calidris canutus and the northern long-eared bat Myotis septentrionalis) or potential status (e.g. the greater sagegrouse Centrocercus urophasianus and the lesser prairie chicken Tympanuchus pallidicinctus), even when they rarely interact with people. At worst, this conflict manifests itself in actual harm to listed species and their habitat, commonly referred to as 'shoot, shovel, and shut up' or 'midnight bulldozing' (Kishida, 2001). To achieve conservation goals, mechanisms to de-escalate conflict and foster coexistence (Fisher, 2016) are needed. 
An important part of finding a solution to this conflict is recognizing that although the media portrays the conflict as human-wildlife conflict, it is actually largely humanhuman conflict. Addressing human-human conflict requires more than the engagement of conservation biologists alone; it necessitates an interdisciplinary approach that engages biologists, social scientists, and practitioners (Redpath et al., 2015), and novel solutions (Fisher, 2016). Conflict resolution approaches that foster dialogue and build trust are essential (Peterson et al., 2010; Young et al., 2010). This approach of stakeholder engagement was effective in the development of a conservation plan for threatened piping plovers nesting on private and state beaches in Massachusetts. The U.S. Fish and Wildlife Service and the Massachusetts Division of Fisheries and Wildlife sought to increase the flexibility of recreational and operational management on beaches with nesting plovers, with a focus on achieving long-term conservation for the shorebird. The plan was approved in 2016 and resulted in positive news media coverage regarding the collaboration between conservation and recreational organizations, towns, and the government. Continued tracking of the public response to this approach could provide important information about whether the approach minimizes or reframes conflict, and monitoring biological impacts will also be critical.

Incentive-based programmes have been created to try to reduce human-human conflict over federally protected species in the USA and internationally, and foster coexistence between wildlife and people. Such programmes may not be compatible with plover conservation, as they focus on habitat as opposed to conservation actions such as limiting human disturbance of birds. One mechanism that is believed to have improved public perceptions of listed species is the Safe Harbor Program (Kishida, 2001; Wilcove \& Lee, 2004), which requires private landowners, who sign up voluntarily, to maintain a baseline population of a threatened species on their lands and enhance the habitat, but absolves them of the responsibility of maintaining listed species that arrive on their land in the future. Similarly, the Working Lands for Wildlife partnership between the U.S. Fish and Wildlife Service and U.S. Department of Agriculture's Natural Resources Conservation Service aims to provide assistance to voluntarily restore and improve habitat on private lands, while also exempting those private landowners from responsibility for impacts to species that may be caused by implementing and maintaining conservation practices. Likewise, compensation programmes in the USA and Europe provide agricultural landowners with financial compensation for losses of livestock or crops to wildlife. To increase support for conservation, programmes have been developed in communities worldwide to increase the benefits of ecotourism and agrotourism for farmers or local community members. More could be learned about how all of these programmes affect human-human conflict situations around protected species, and whether they minimize framing of the conflict as being between humans and wildlife.

Strategic communication efforts may help de-escalate conflict, yet more needs to be known about what drives the media and other audiences to frame wildlife as being to blame. Better understanding of the extent to which the public perceives the plover and other protected species as being to blame, and the attitudes and beliefs associated with such a view, could help inform targeted messaging to these audiences, or segments of these audiences. Alternatively, it may be that certain groups of people who blame wildlife species cannot be influenced by communication messages because of strongly held beliefs, and therefore other approaches to conflict mitigation are needed.

We recommend that this research be extended beyond the USA. There is more to be learned both nationally and globally through cross-cultural research (Manfredo \& Dayer, 2004). We recommend exploring conflict over species conservation and management in multiple countries, where researchers could utilize natural experiments in various settings with various types of legislation for wildlife conservation. Researchers could answer questions, for example, about what characteristics of wildlife protection policies (e.g. level of government, strength of enforcement, types of stakeholder engagement) lead to more or less pronounced conflict and media framing as human-wildlife or humanhuman conflict, providing guidance for how to work most effectively with people and communities to conserve species.

\section{Acknowledgements}

We thank the U.S. Fish and Wildlife Service, Northeast Region for the funding provided for this research. The findings and conclusions in this article are those of the author(s) and do not necessarily represent the views of the U.S. Fish and Wildlife Service.

\section{Author contributions}

AAD developed the methods, conducted the quantitative analyses, and was the lead writer and editor. AW and EC reviewed literature, drafted sections of the article, wrote the coding scheme, and conducted qualitative analysis of the articles. MR identified the need for the project, coordinated with the media intelligence firm, and drafted sections of the article.

\section{References}

BENSON, R.D. (2002) Giving suckers (and salmon) an even break: Klamath Basin water and the Endangered Species Act. Tulane Environmental Law Journal, 15, 197-238. 
Bhatia, S., Athreya, V., Grenyer, R. \& Macdonald, D.W. (2013) Understanding the role of representations of human-leopard conflict in Mumbai through media-content analysis. Conservation Biology, 27, 588-594.

Bohensky, E.L. \& Leitch, A.M. (2014) Framing the flood: a media analysis of themes of resilience in the 2011 Brisbane flood. Regional Environmental Change, 14, 475-488.

Bornemeier, J. (1995) Bipartisan bid to revamp Endangered Species Act introduced in House. Los Angeles Times, Http://articles.latimes. com/1995-09-08/news/mn-43545_1_endangered-species-act [accessed 26 May 2017].

Brook, A., Zint, M. \& De Young, R. (2003) Landowners' responses to an Endangered Species Act listing and implications for encouraging conservation. Conservation Biology, 17, 1638-1649.

BROWn, JR, G.M. \& SHOGREN, J.F. (1998) Economics of the Endangered Species Act. The Journal of Economic Perspectives, 12, 3-20.

Dickman, A.J. (2010) Complexities of conflict: the importance of considering social factors for effectively resolving human-wildlife conflict. Animal Conservation, 13, 458-466.

Feldpausch-Parker, A.M., Burnham, M., Melnik, M., Callaghan, M.L. \& Selfa, T. (2015) News media analysis of carbon capture and storage and biomass: perceptions and possibilities. Energies, 8, 3058-3074.

Fisher, M. (2016) Whose conflict is it anyway? Mobilizing research to save lives. Oryx, 50, 377-378.

Gore, M.L. \& KNUTh, B.A. (2009) Mass media effect on the operating environment of a wildlife-related risk-communication campaign. The Journal of Wildlife Management, 73, 1407-1413.

Gore, M.L., Siemer, W.F., Shanahan, J.E., Schuefele, D. \& DECKER, D.J. (2005) Effects on risk perception of media coverage of a black bear-related human fatality. Wildlife Society Bulletin, 33, 507516.

Gray, G.G. (1993) Wildlife and People: The Human Dimensions of Wildlife Ecology. University of Illinois Press, Urbana, USA.

Houston, M.J., Bruskotter, J.T. \& Fan, D. (2010) Attitudes toward wolves in the United States and Canada: a content analysis of the print news media, 1999-2008. Human Dimensions of Wildlife, 15, $389-403$.

Jorgensen, J.G. \& Bomberger Brown, M. (2015) Evaluating recreationists' awareness and attitudes toward piping plovers (Charadrius melodus) at Lake McConaughy, Nebraska, USA. Human Dimensions of Wildlife, 20, 367-380.

Kishida, D. (2001) Safe harbor agreements under the Endangered Species Act: are they right for Hawai'i?. Environmental Law Program, University of Hawai i, USA.

Lueck, D. \& Michael, J.A. (2003) Preemptive habitat destruction under the Endangered Species Act. Journal of Law and Economics, XLVI, 27-60.

Macnamara, J. (2005) Media content analysis: its uses, benefits and best practice methodology. Asia Pacific Public Relations Journal, 6, 1-34.

Madden, F. (2004) Creating coexistence between humans and wildlife: global perspectives on local efforts to address humanwildlife conflict. Human Dimensions of Wildife, 9, 247-257.

Maguire, G.S., Rimmer, J.M. \& Weston, M.A. (2013) Stakeholder perceptions of threatened species and their management on urban beaches. Animals, 3, 1002-1020.

Manfredo, M.J. \& Dayer, A.A. (2004) Concepts for exploring the social aspects of human-wildlife conflict in a global context. Human Dimensions of Wildlife, 9, 1-20.
Messmer, T.A. (2000) The emergence of human-wildlife conflict management: turning challenges into opportunities. International Biodeterioration \& Biodegradation, 45, 97-102.

Peterson, M.N., Birckhead, J.L., Leong, K., Peterson, M.J. \& Peterson, T.R. (2010) Rearticulating the myth of human-wildlife conflict. Conservation Letters, 3, 74-82.

Prasad, B.D. (2008) Content analysis: a method in social science research. In Research Methods for Social Work (eds D.K. Lal Das \& V. Bhaskaran), pp. 173-193. Rawat, New Delhi, India.

Priest, S. (2015) Media portrayal of risk: the social production of news. In The SAGE Handbook of Risk Communication (eds H. Cho, T. Reimer \& K.A. McComas), pp. 208-215. SAGE Publications, Inc., Thousand Oaks, USA.

Redpath, S.M., Bhatia, S. \& Young, J. (2015) Tilting at wildlife: reconsidering human-wildlife conflict. Oryx, 49, 222-225.

Scheufele, D.A. \& Tewksbury, D. (2007) Framing, agenda setting, and priming: the evoloution of three media effects models. Journal of Communication, 57, 9-20.

Scott, J.M., Csuti, B., Jасовi, J.D. \& Estes, J.E. (1987) Species richness. BioScience, 37, 782-788.

TANkARD, JR, J.W. (2001) The empirical approach to the study of media framing. In Framing Public Life: Perspectives on Media and our Understanding of the Social World (eds S.D. Reese, O.H. Gandy, Jr \& A.E. Grant), pp. 95-106. Lawrence Erlbaum Associates, Inc., Mahwah, USA.

Thompson, JR, B.H. (1997) The Endangered Species Act: a case study in takings \& incentives. Stanford Law Review, 49, 305-380.

Treves, A., Jurewicz, R.R., Naughton-Treves, L., Rose, R.A., Willging, R.C. \& Wydeven, A.P. (2002) Wolf depredation on domestic animals in Wisconsin, 1976-2000. Wildlife Society Bulletin (1973-2006), 30, 231-241.

USFWS (U.S. Fish and Wildlife Service) (1996) Piping Plover (Charadrius melodus), Atlantic Coast Population, Revised Recovery Plan, pp. 59-81. USFWS, Hadley, USA.

Wilcove, D.S. \& LeE, J. (2004) Using economic and regulatory incentives to restore endangered species: lessons learned from three new programs. Conservation Biology, 18, 639-645.

Woodroffe, R., Thirgood, S.J. \& Rabinowitz, A. (2005) People and Wildlife: Conflict or Coexistence?. Cambridge University Press, Cambridge, UK.

Young, J.C., Marzano, M., White, R.M., McCracken, D.I., Redpath, S.M., Carss, D.N. et al. (2010) The emergence of biodiversity conflicts from biodiversity impacts: characteristics and management strategies. Biodiversity and Conservation, 19, 3973-3990.

\section{Biographical sketches}

Ashley DAYer studies the human dimensions of bird conservation, with an emphasis on issues of private lands, conflict, recreation, communications and citizen science. She is also interested in the gap between conservation science and implementation. Alicia Williams is interested in the social behaviour of birds and the impact of methane on the environment. EmILY CosBaR's interests include the applications of conservation science in non-profit and private sectors, related to conflict, land stewardship, coastal biodiversity, and clean energy. MEAGAN RACEY focuses on how research can guide effective conservation communication efforts, particularly related to threatened species. 